Published 2018 In: Berys Gaut and Matthew Kieran (eds.) Philosophy and Creativity (New York: Routledge).

\title{
Artistic Creativity and Suffering
}

\author{
Jennifer Hawkins
}

Can negative psychological experiences be good for a person? If so, what could possibly be good about them? And when and under what circumstances might they be good? In what follows, my aim is to begin a philosophical exploration of these issues by focusing on a particular case - the relationship between negative affective experience and artistic creativity.

There is a strong, empirically documented link between artistic creativity and psychiatric mood disorders (Jamison 1996; Andreasen 1987; Richards et al. 1988; Jamison 1989; Ludwig 1994; Post 1996; Kaufman \& Baer 2002; Kyaga et al. 2011; Kyaga et. al. 2013). Though no one knows why, it is now well established that poets, fiction writers, visual artists and musicians are much more likely than ordinary people to suffer from either manic-depressive illness (bi-polar disorder) or unipolar depression. ${ }^{1}$ To give but one example, Jamison (1996) found rates of depression 8 to 10 times higher in artists and writers than in the rest of the population. In addition, some people believe that the link between artistic creativity and mental illness may be tight: that darkly negative moods may turn out to be necessary for artistic creative expression (Jamison 1996).

If this were true, ${ }^{2}$ it would raise interesting questions about prudential value, i.e. about what is (extrinsically) good for certain creative individuals. ${ }^{3}$ Many people not only value the creative products of others, they value being creative. Indeed, most people assume that an individual's production of works of art is something that is good for her. But if creative production is good for a person and negative experience bad-though 
Published 2018 In: Berys Gaut and Matthew Kieran (eds.) Philosophy and Creativity (New York: Routledge).

necessary for creative production - this raises interesting, highly complex questions about whether and when such experiences may be all-things-considered worth it. Nor are these merely abstract questions.

Consider issues relating to treatment. Creative individuals who have recurring bouts of major depression or of manic-depressive illness are typically candidates for psychiatric treatment that, in many cases, could eliminate or at least seriously mitigate their suffering. Yet such individuals sometimes choose to forgo treatment, particularly medication. The reasons are complex. Not all people respond to current medications, and many medications have side effects unrelated to creativity (e.g. weight gain, dry mouth, tremors, loss of libido) that individuals understandably dislike. ${ }^{4}$ But it remains true that many people are wary of medication because they fear the effects of treatment on their creative lives. If that is so, then even if we develop new medications that lack the unpleasant side effects, such worries will persist.

Some people can't understand how negative experiences of the sort tolerated by such individuals could have value. Surely, they assume, a person with a severe mental illness should welcome anything that might curb it. However, as a general conclusion this is too strong. It reveals a lack of insight into the many different things individuals value about their lives, including the very real value that artistic productivity adds.

However, the opposite general conclusion - that anything is worth enduring for the sake of art—is equally unjustified and equally lacking in insight. Still, some people adopt it. There are people who are virulently anti-treatment and who seem to assume that creativity is a kind of sacred value, not to be weighed against, or compared with, any others. This latter mentality is well illustrated by an anecdote from the psychiatrist Peter 
Published 2018 In: Berys Gaut and Matthew Kieran (eds.) Philosophy and Creativity (New York: Routledge).

Kramer. Kramer reports that when he was giving talks about his book Listening to Prozac, he repeatedly encountered the same question. "With discouraging reliability" he reports, someone from each audience would ask, "What if Prozac had been available in van Gogh's time? (2005: 31)" In each case, the question was presented as a challenge, as a kind of reductio of the claim that medication to relieve negative psychological states is typically good. The questioners assumed that there was at least one clear set of cases where medication would not be good, namely, cases involving artists. Although the point was partly about how the widespread use of medication among artists would not be good for the rest of us (because we would collectively lose so much great art), it was also clearly meant to underscore the badness of medication for individual artists themselves.

In what follows, I shall set aside concerns about the good of others and focus on the question of when (if ever) negative experiential states might be good for a particular creative individual. I take it that concern for the individual morally trumps concern about the value for the world of great art. If a particular life path would be (overall) bad for someone, or significantly worse for her than some other easily available path, then we should not encourage her to pursue the worse path, even if great art is thereby lost. Proper concern for an individual requires concern for her welfare for its own sake. Of course, individuals themselves may wish to pursue certain goods knowing that the pursuit is against their own best interests. I do not assume that most people do or even ought to care most about their own good.

A few clarifications are necessary. First, it is important to distinguish between negative affective experience and suffering. I use 'negative experience' and similar terms to refer to the broad category of negative affective states and reserve the word 'suffering' 
Published 2018 In: Berys Gaut and Matthew Kieran (eds.) Philosophy and Creativity (New York: Routledge).

for the more extreme forms of such experience. Since both refer to psychological states, neither is the same as adversity. Adversity is non-mental and refers to negative events in a person's life, the kinds of events that make a life difficult such as illness, poverty or unfortunate accidents. Though adversity can and often does lead to negative experience, and even suffering, this is not always the case.

Many discussions of the lives of creative people run together adversity and negative psychological experience. We are all familiar with stories about famous artists who have had to endure many hardships on the way to success. Poverty and lack of recognition are common, which is why the phrase "starving artist" has become a familiar trope. But not all artists who experience hardships suffer. My question is not about the value of hardship. It is a general question about the value of negative psychological states, and a particular question about the value (if any) of intense psychological distress.

Second, although I focus here on questions about prudential value or well- being, I neither argue for, nor assume the truth of, any particular theory of well- being. I do assume that psychological states are among the things that matter prudentially, but not that they are the only things that matter. ${ }^{5}$

In what follows, I want first to consider what it would take to establish that negative psychological experiences (of any sort) have significant extrinsic value. More specifically, what would we want to know before choosing to endure such experiences for the sake of some other good? I also want to develop a framework to help us distinguish between different types and levels of negative psychological experience and then ask of the more extreme forms of negative experience whether they are ever worth enduring. Ultimately, I argue that it can only rarely (if ever) be worthwhile to endure 
Published 2018 In: Berys Gaut and Matthew Kieran (eds.) Philosophy and Creativity (New York: Routledge).

suffering for the sake of creativity (or for that matter any other good).

\section{§1.0 What Sort of Connection?}

What is the connection between negative experiential states and creativity? No one is sure exactly, since there is so much conflicting data. Still it is possible to say a bit by way of clarifying the possibilities.

First, however, I need to address a couple of potential confusions. To begin with, even those theorists who think there may be a necessary connection between negative experiential states and creativity do not claim that this is a connection that holds for all creative people. Obviously there are many creative people who never exhibit any signs of mental illness or even signs of milder negativity. So the claim cannot be that negative affective experience is generally necessary. Rather, the idea is that for particular individuals — given the way they are constituted—it might turn out that negative affect is a necessary part of the path they must follow to realize their creative potential. For these individuals, even if not for others, there is no path to creative expression free from (some degree of) psychological disturbance.

Second, the claim that negative affect might be necessary for creativity is not the claim that periods of negative affect are themselves periods of creative production. It is well known that most people produce little or nothing during depressive episodes. As Kieran (2014) reminds us, "Virginia Woolf could barely write when depressed, Van Gogh was unable to paint when in seemingly similar states and Coleridge suffered a deeply paralyzing writer's block for years due to anxiety." ${ }^{\prime 6}$ The general idea with respect to artistic creativity is just that negative experiences might be part of the path that leads to 
Published 2018 In: Berys Gaut and Matthew Kieran (eds.) Philosophy and Creativity (New York: Routledge).

creative production, where the production in question could just as easily occur at a later time, once the person is no longer severely depressed or anxious. The negative affect and the creative production need not occur simultaneously (Richards 1981; Jamison 1996).

There are several different ways one might think about the relationship between negative affect and creativity. On one view, which I shall call the bundle theory, certain individuals must pass through negative states in order to create (presumably, at some later time). On this view, negative experience does not contribute directly to the creative process, but is an element in a bundle of elements where the particular elements cannot (for whatever reason) be separated from one another (at least not currently). The individual must either accept the whole package or none of it. This might be the case, for example, if we were to discover that in certain individuals with affective mental illness, negative affect and creative thought processes were two different, independent effects of a single underlying disease process. ${ }^{7}$ We would then be interested in knowing whether we could eliminate one, but only one, of the two effects. It would be nice if this were possible. If it were, then negative affect would not be necessarily linked to creativity. But there are no guarantees that the two would be separable. It is an empirical question whether the bundle model is even the right model. But even if it were, it would be a further empirical question whether one effect (negative psychological states) could be suppressed without altering the other (the creativity). The messy reality of human biology might not allow it. If that were true, then negative affect would be (at least for certain individuals) an ineliminable part of creative production.

The second view of the relationship between creativity and negative experiences is what I shall call the special ingredient view. ${ }^{8}$ On this account, negative experiences 
Published 2018 In: Berys Gaut and Matthew Kieran (eds.) Philosophy and Creativity (New York: Routledge).

are not just by-products of something else that enables creativity-they actually contribute to creativity directly. On this view, negative affective experiences are necessary for creative production in the way that certain ingredients are necessary for the creation of good food. More concretely, the idea is that something specific is gained or learned or acquired during the passage through negative states, something that then influences the individual's subsequent work. Whereas on the first model negative experience is unavoidable but not a causal contributor, on the second model it is a contributor and this fact explains its unavoidability.

One might wonder what could possibly be gained or acquired from negative experiences, especially deeply negative ones. Since many artists have suffered from bipolar disorders, there is a natural tendency to assume that if there is a contribution to creativity from the illness, it is a contribution that comes from the manic side (Jamison 1996: 118). ${ }^{9}$ Yet, although manic tendencies and the experiences they create may also contribute to artistic production in important ways, many artists nonetheless insist that their negative experiences—-their depressions and anxieties—are key as well. ${ }^{10}$ What then might deeply negative experiences contribute?

One hypothesis is that since so much artistic work is about the expression of emotion, artists who have deeper and wider experience of extremes of emotion may gain from their experiences a kind of emotional insight or knowledge that improves their creative work. ${ }^{11}$ Of course, the kinds of emotional experiences produced by affective illness are typically extreme, so one might wonder why one would need experience of the extremes to create good art. Presumably great art speaks to large numbers of people by capturing and reflecting something of their experiences, giving powerful expression to 
Published 2018 In: Berys Gaut and Matthew Kieran (eds.) Philosophy and Creativity (New York: Routledge).

something they could not have expressed so well themselves. But if, as seems likely, the extremes of experience are not the experience of most, it is not clear why intimate knowledge of extremes would improve art or enable artists to speak to a wider audience.

One possibility is that most of us can only recognize, and so can only begin to learn from and interpret, our own experiences when these are presented to us in more dramatic, larger-than-life forms. A certain degree of grandiosity and exaggeration are needed to enable us to foreground and become aware of the features of our own emotional life, features that so easily slide into the background. On this view, we become familiar with the subtleties of the human emotional landscape by having it presented to us on a grand scale. If our own appreciation for sorrow (which is an inevitable aspect of human life) is deepened by contact with work that paints sorrow in powerful ways, and if the ability to express sorrow in those ways depends on experiencing it in its extremes, then this might be an explanation of the way in which negative experience gives artists something important and essential.

It is also well known that mood is relevant to the way the mind stores and then later accesses information (Morris 1999: 172-4; Schacter 1996: 209-212). Current mood influences what you retain now for the future and also influences now what you can access about your past. When a person is in a good mood, she focuses on and forms more memories about the positive aspects of whatever is happening to her. When she is in a negative mood, the opposite is true. But also, when a person is in a good mood, she can more easily access information about positive aspects of her past and is unlikely to spontaneously remember much that is negative. But when she is in a negative frame of mind, the opposite holds: she then has greater access to her negative memories. Because 
Published 2018 In: Berys Gaut and Matthew Kieran (eds.) Philosophy and Creativity (New York: Routledge).

different affective states make different material accessible, some theorists have hypothesized that frequent swings of emotion might give an individual a creative advantage by giving her access to more, different memories and ideas. And indeed, fluidity of thought and the generation of numerous ideas are associated with creativity. Frequent swings might also give an individual more of an ability to adopt differing perspectives on the very same events in her life, which might also contribute to important insights.

One final putative "benefit" of negative affect is worth mentioning, because I doubt it really is one. It is often said that depressed people have a more realistic picture of the world. The value of negative affect (it is said) is that it allows a person to see the world as it is, whereas others are, to a greater or lesser extent, deluded about the state of the world. This is not a new idea, but one found in many subtle variations in both literature and philosophy. The following lines from Herman Melville offer (one of many) example(s): "In [the] flashing revelations of grief's wonderful fire we see all things as they are, and though when the electric element is gone, the shadows once more descend and the false outlines of objects again return, yet not with their former power to deceive (1996 [1852]: 88)" On one reading, Melville is claiming that grief provides general insight into the real nature of things ("we see things as they are"). But interpreted literally, this is too strong. No doubt there is an element of truth in this idea, but only an element.

No doubt part of what Melville has in mind is the way in which grief or despair can re-acquaint us with very real truths that we often ignore-for example, truths about our own mortality and the mortality of those we love. But this is compatible with the 
Published 2018 In: Berys Gaut and Matthew Kieran (eds.) Philosophy and Creativity (New York: Routledge).

thought that negative states do not provide 'the' authoritative perspective on reality. The world contains both good and horrible things, and there is no reason to embrace the idea that the thoroughgoing negative perspective is correct, or even the idea that it is more congruent with how things are. Thus, although depression can put us in touch with truths we often forget, it can simultaneously put us out of touch with others. The idea that negative affect might enhance one's ability to see things "as they are" has gained a certain currency in recent years because of the psychological thesis known as "depressive realism (Alloy \& Abramson 1979)." However, these days many psychologists are skeptical of depressive realism (Ackermann \& DeRubeis 1991; Haaga \& Beck 1995; Dobson \& Pusch 1995; Peterson 2006: 95-6).

Though I do not doubt that negative affect may have some benefits, particularly for creativity, I am deeply skeptical of the widespread tendency to over- state the case. A common theme in discussions of depression is what the psychiatrist Peter Kramer (2000) has called "the valorization of sadness." ${ }^{, 2}$ Building from the idea that people in the grips of negative affect are more in tune with reality, the suffering of such individuals is then viewed as, in some sense, elevated and noble. Though they suffer, they see what the rest of us do not. We should resist such romanticized, overblown generalizations and instead look for ways to concretely assess what is gained and lost in negative states.

\section{\$2.0 Assessing the Value of Negative Experience}

Having considered how negative affect and creativity might be linked and having argued that it is at least plausible that such a link might be necessary, at least for certain people, I want to consider what this might mean for prudential decision- making. Might it 
Published 2018 In: Berys Gaut and Matthew Kieran (eds.) Philosophy and Creativity (New York: Routledge).

ever be worth it, all-things-considered, to endure negative states for the sake of what is gained from them? Here I want to offer a few, general observations about choosing negatives for the sake of positives.

It is extremely important to distinguish two different perspectives we can adopt on decisions: the prospective perspective and the retrospective one. What we know prospectively is often limited, and so we must choose in the face of great uncertainty, on the basis of our best information. However, most of our experience (such as it is) with judging the value of bad events comes from the retrospective perspective. If I am trying to understand (prospectively) whether, and if so when, it might make sense to tolerate negatives for the sake of positives, I may well turn to the stories and accounts of those who have experienced similar negatives, looking to see whether they view their experiences as having been worth it. But there are potential dangers involved in listening to those who occupy the retrospective perspective. Moreover, certain questions, which it is important to consider prospectively, do not arise from the retrospective standpoint.

One common barrier to thinking clearly about the value of negative experiences stems from the fact that we are—most of us at least—strongly motivated to look for good in the midst of bad. To focus on good things and, in some cases, to create something new and good out of a bad experience is comforting. It allows an individual to feel better, to move on, and to view her own continuing narrative in positive terms. All of this is understandable, and in many instances the things it spurs individuals to accomplish are admirable. But it does mean that we are inclined to think that our negative experiences have contributed to later good outcomes, even when they have not. Thus, what people say on this score should be viewed with a degree of caution. There will be tendencies to 
Published 2018 In: Berys Gaut and Matthew Kieran (eds.) Philosophy and Creativity (New York: Routledge).

exaggerate the extent of the link and to see (with hindsight bias) more value than is really there.

One extremely important question that should be considered prospectively is whether one has reason to think that the good one is aiming at will really outweigh the negatives one will have to endure to reach it.

Importantly, this is the kind of question that rarely arises for those thinking about matters retrospectively. If a negative event in our life is already a given—something we cannot alter - then while we may be interested in whether the negative event ultimately contributed to something positive, we have little reason to inquire too precisely into the relative weights of the values. If we do raise such issues, we will be biased in favor of viewing the good as fully compensating the bad whether it did or not. After all, that makes for a much better, much more comforting personal story. So again, we must be somewhat cautious when it comes to accepting as guidance for our own lives the retrospective reports of others.

A second important question is whether the negatives are really necessary in this case. After all, it might not be true of all individuals that they need negative affective experiences in order to be creatively productive. And even if they do need some of this, it is worth questioning whether they need the kind and degree of it that, left untreated, they will likely experience. Once again, this is not the kind of question that naturally arises from the retrospective perspective, since again, if a negative event that contributed to a good one has already occurred and cannot be changed, we have little motivation to discover whether the same good outcome might have been had with a less negative initial event. But prospectively, this makes a lot of difference. For even if we grant that it can 
Published 2018 In: Berys Gaut and Matthew Kieran (eds.) Philosophy and Creativity (New York: Routledge).

sometimes make sense to choose suffering for the sake of some good it will help bring about, there is still no reason to endure more suffering than is strictly necessary.

A third important question is whether there are other possible paths through life that will be just as good or better than the creative path, albeit different in the particular goods they contain. Suppose that an individual faces the following choice. If she remains without treatment for her depression she will have recurring bouts of it. But during the periods when she is not depressed, she will be able to pursue her art. Suppose that if she accepts treatment, her depressions will be lifted, but that her artistic expression will benot absent, but—blunted, different, neither as intense nor as good as before. Suppose also that she would find that frustrating, so much so that if she pursues the treatment path she would really be better off overall doing something else. Finally, suppose that if she received treatment she could pursue an interesting non-artistic career (she has the talents or abilities for that career), and she could have other goods as well—significant and longlasting relationships and so on. In short, as I imagine it, it is possible for the person she is to find great fulfillment in other things, whether she currently realizes that or not. Although the goods in this alternative life path would be very different in kind from the artistic goods she currently pursues, it might well be that there is much more overall good for her in the alternative life. My point is simply that if that is the case, then she should pursue the alternative.

Everything, of course, turns on one's theory of well-being, and what elements one views as possessing prudential value and how much. Theorists could agree in principle to the idea that she ought to pursue an alternative non-creative path with more overall value in it, but be unable to agree on what kind of life would actually count as containing more 
Published 2018 In: Berys Gaut and Matthew Kieran (eds.) Philosophy and Creativity (New York: Routledge).

overall value. But we should not confuse the disagreements of theorists of well-being (about what kinds of goods can compensate for which others), with the not-uncommon lay-person's rejection of the very idea that a significantly different alternative could be just as good. It can be very tempting for an individual already launched on a particular path to assume that no other path could possibly be as good for her as the one she currently wants to pursue or is pursuing. But as theorists we should we wary of accepting such claims. There are many wonderful ways for a life to go even though much of the personal goodness of a particular type of life is only fully appreciated by those who are currently living it. This makes it hard for individuals to appreciate that possible lives quite distinct from their current one might nonetheless - if they were living that lifestrike them as being just as good if not better.

\section{§3.0 Suffering and Its Place in Mind}

I have so far pointed out various problems that confront us when we think about the value of negative experiences. We are inattentive to trade-offs, prone to retrospective biases and sometimes tempted to valorize negative experiences. But by far the largest problem is not having a sufficiently rich vocabulary for talking about negative experiences. Most people associate the word 'suffering' with physical pain, but although real and important, pain is not the only form of suffering. We have too little understanding of psychological distress and no good account of which types are worse than others.

As part of helping us become better at distinguishing different types of negative experience, I wish to introduce a particular kind of mental phenomenon, what I shall call 
Published 2018 In: Berys Gaut and Matthew Kieran (eds.) Philosophy and Creativity (New York: Routledge).

a personal perspective (or just perspective, for short). To bring out some of the characteristic features of affect generally, and perspectives in particular, I will locate them in a dual-process picture of mind (Kahneman 2012). ${ }^{13}$ This is a view that has come to be widely accepted among psychologists, according to which the mind has two semiindependent systems of thought.

One system (System 1) is extremely fast, its processes largely (though not always) unconscious, and involuntary. The other system (System 2) is slower, more effortful, conscious and voluntary. One of the primary roles of System 1 is to acquire and pre-sort for personal relevance information about the environment. It also offers System 2 suggestions about what to believe, whether to judge things negatively or positively, and how to act. One of the primary roles of System 2 is to take the suggestions of System 1, refine them, and elaborate upon them. It is also the job of System 2 to periodically question the offerings of System 1 and reject flawed suggestions. System 1 and System 2 are both systems of thought, which means that they are both in the business of generating representations of the world. They produce mental states with content, albeit of quite different kinds.

There are several advantages to adopting this dual process picture. First, there are certain kinds of mental states that are best understood if they are characterized in System 1 terms: as fast, intuitive, involuntary. Affective processes are like this. We get something deeply wrong if we fail to understand the way in which affective phenomena are both fast, intuitive and (for the most part) out of our control. Second, even apart from the particular characteristics of each system, it is important to recognize the existence of two systems of thought. For it is only by postulating two quasi-independent systems that we 
Published 2018 In: Berys Gaut and Matthew Kieran (eds.) Philosophy and Creativity (New York: Routledge).

can begin to offer adequate explanations of internal mental conflict. Though the two usually work in harmony, System 1 and System 2 do not always agree.

Personal perspectives are affective. ${ }^{14}$ However, a perspective is neither an emotion nor a mood. For one thing, perspectives typically last longer than either emotions or moods. But perspectives are also more basic and more comprehensive. They are more basic in the sense that a person's perspective contributes to determining the particular emotions and moods she experiences. A perspective is more comprehensive in the sense that its ability to color our perception of the world is more extensive. Currently there is no general, agreed upon vocabulary for identifying and discussing perspectives. This is part of what I wish to change.

So what is a perspective? As we saw, System 1 constantly monitors the environment and acquires information. It forms quick assessments of things it deems relevant to the individual. Some of these assessments are conscious, but even those that are not have the potential to impact consciousness in a variety of ways. However, only a sub-set of System 1 assessments are relevant to personal perspectives. These fall into three broad categories: (1) assessments of objects of care, (2) assessments of self, and (3) assessments of the future. I will explain each in turn.

Recall that our affective capacities are what enable us to care about things in the world. To care about things (in the basic sense that interests me) does not require great cognitive sophistication. We can care about people, objects, sensations, goals, activities, events, relationships, achievements, etc. Affect is what enables us to emotionally 'latch on' to things that we encounter in the world. For most of us, as we grow, our ability to be concerned about things expands greatly. To understand a personal perspective, however, 
Published 2018 In: Berys Gaut and Matthew Kieran (eds.) Philosophy and Creativity (New York: Routledge).

we must focus on the smaller set of things that an individual cares about in the most basic, emotional sense. These are the things that can elicit reasonably strong emotions. The contrast should be familiar enough: suppose two children are hurt in an accident, my own child and the child of a stranger. I understand that both events are bad. But only one affects me deeply because only my child is an object of care (in this special, defined sense) for me.

An individual's personal perspective is partly shaped by the assessments that her mind makes with respect to these objects of care. System 1 constantly tracks and monitors these and anything that might affect them. In extreme cases (if an object of care is, for example, threatened) an emotional reaction may occur. But discrete emotions are the unusual event. More often there is just a stream of information coming in, which is to one degree or another positive or negative. In light of this information, slight adjustments in outlook are made. If things generally appear well with respect to the objects of care, then the person's perspective will be more positive and she will feel better. To the extent she is aware of problems or losses, her perspective will be more negative and she will feel worse.

The second set of relevant assessments are System 1 assessments of the self. These intuitive, involuntary assessments occur frequently, where the self is held up to and compared with some standard or norm. These need not be reasonable norms, or norms widely accepted by others, though they often are. In addition, some people are more likely to notice the ways in which they have exceeded norms whereas others are more likely to notice ways in which they have fallen short. The cumulative effect over time of many such self-assessments is a positive or negative self-picture, which in turn, is an 
Published 2018 In: Berys Gaut and Matthew Kieran (eds.) Philosophy and Creativity (New York: Routledge).

element of personal perspective.

A third category of assessment concerns the future. When an individual thinks about the future, does she tend to assume that things will go well or go badly? Even when a person is not explicitly engaged in trying to think about the future, many events during the course of a day will trigger at least momentary assessments of how things are likely to go, what might be about to happen: How a relationship is likely to develop, how an interview is likely to turn out, whether or not a call is likely to be good or bad news. These assessments of the near and far future cumulatively contribute to personal perspective. To the extent that more such assessments are negative, the person's perspective will be more negative as well. And vice versa with positive assessments.

All three types of intuitive assessment occur constantly, generating for the individual an overall picture of how things stand with respect to what matters to her. This is by no means her whole view of the world. But it is the best predictor of her emotional life.

I suggest that we think of personal perspectives as existing along a continuum from highly positive to highly negative. Here is one way we might try to make this idea concrete. Presumably for any given individual there is some total number of intuitive assessments that her System 1 makes over the course of a day. And there must be some determinate subset of these that are relevant to her personal perspective in the ways described above. Call these the perspective relevant assessments. For a given individual and a given day there must then be an answer to the question: what percentage of her perspective relevant assessments are either positive in themselves or contribute to maintaining a positive outlook? We can then locate particular perspectives along a 
Published 2018 In: Berys Gaut and Matthew Kieran (eds.) Philosophy and Creativity (New York: Routledge).

continuum ranging from highly positive at one end (meaning that a high percentage of the perspective relevant assessments are positive) to negative at the other (meaning a very low percentage of the perspective relevant assessments are positive). On this model, we all of us, all of the time, occupy some personal perspective or other.

The continuum is defined in terms of daily degree of positivity. But of course we are most often interested in patterns that extend over time: perspectives that persist. The framework allows us to do this if we simply plot the daily figures over time. For most people, most of the time, perspectives are relatively stable. So although the numbers for any given individual will change slightly from day to day, they will presumably tend over time to be clustered in the same relatively narrow range of the continuum, unless some dramatic shift occurs. And of course, big shifts do occur. It is well known that personal events viewed by the individual as very good or very bad (e.g. success in a big project, the death of a loved one) can rapidly alter perspective. Changes can also come about because of changes internal to the person, as happens, for example, at the onset of affective illness. Once we have the idea of a continuum we can adopt quasi-stipulative definitions of ranges. We can distinguish on the negative side between suffering and mere unhappiness, and on the positive side between mild happiness and more intense happiness.

I have deliberately sought to devise a way of talking about affective perspectives that is independent of the ways in which such perspectives are generated and also independent of the extent to which the perspective tracks reality. A person can occupy a horrible personal perspective if everything she cares about is going horribly (think of someone in a concentration camp). Or she can occupy a horrible perspective because she 
Published 2018 In: Berys Gaut and Matthew Kieran (eds.) Philosophy and Creativity (New York: Routledge).

is in the grips of the severest of depressive episodes. The continuum I have described gives us a useful way of comparing and contrasting particular perspectives in terms of their degree of positivity and allows us to talk about the connection between individual perspectives and welfare.

My thesis is simply that it is intrinsically bad for an individual to occupy a bad personal perspective, in much the same way it is intrinsically bad for an individual to be in pain. Likewise it is intrinsically good for someone to occupy a positive one. ${ }^{15}$ Perspectives are not the only intrinsic prudential values, but they are extremely important ones. The degree of badness (or goodness) is a function of the location of the perspective on the continuum. The less positivity there is in a perspective, the worse that perspective is for the individual who occupies it. It is important to grasp that occupying an extremely negative perspective feels very bad. We just are evaluative creatures who respond well and feel well when we can 'see' positives in the world. We wither in the absence of any such perception. Whereas philosophy contains much discussion of the badness of physical pain, it is all too easy for the intrinsic badness of personal perspectives to be overlooked.

\section{§4.0 Important Errors to Avoid}

Our lack of nuanced distinctions in negative psychology contributes to our inability to fairly assess the value of negative experiences. Knowing whether a negative experience is "worth it" requires assessing whether the prudential goods that come with it fully compensate for it. But since different negative experiences have quite different degrees of prudential disvalue, no accurate assessment is possible unless we are clear 
Published 2018 In: Berys Gaut and Matthew Kieran (eds.) Philosophy and Creativity (New York: Routledge).

about the kind of experience in question. Two particular types of error are worth highlighting: (1) failures to distinguish between types and degrees of negative affect and (2) failures to distinguish between negative affect and negative non-affective thought. I will describe each type of error briefly.

It is easy for people to confuse negative moods with negative perspectives, and to confuse mildly negative perspectives with more severe ones. We all experience negative moods. These are transient shifts within more stable affective perspectives. A negative mood occurs when an individual's general pattern of appraisal is temporarily disrupted, resulting in fewer positive appraisals and (perhaps) more negative ones. The difference between moods and perspectives, however, is not simply temporal. Perspectives last longer, but they are also more encompassing. A person can be in a bad mood, without it affecting most of the appraisals central to her personal perspective. Moods color our perception of some things, but perspectives color our perception of many things, including the ones most central to us. Similarly, it is important to realize that mildly negative perspectives are quite different from severely negative ones. It would take an incredible amount of prudential good to make it worthwhile to occupy a severely negative perspective.

It is also worth calling attention to the possibility of System 1/System 2 dissonance. When we see a person prone to negative thoughts, we are usually correct in assuming that his stated thoughts are reflections of his feelings-i.e. of his negative affective perspective. After all, System 1 appraisals are usually taken up and incorporated into System 2 thinking. But sometimes System 1 and System 2 come apart. It is possible for a person to express many negative thoughts despite not feeling bad. Indeed, it is 
Published 2018 In: Berys Gaut and Matthew Kieran (eds.) Philosophy and Creativity (New York: Routledge).

possible for an extremely negative person at the level of System 2 to be someone who is actually quite happy. Admittedly, much empirical evidence suggests that the type of person prone to negative thinking is more vulnerable to developing depression or other affective disorders. But being at risk for something is not the same as actually developing it. Consider the following case:

Paul is by nature a very serious person and because of this he is not prone to displays of positive affect. He doesn't smile a lot. He is not effusive. He works in a clinic that serves the health needs of the very poor. He has a deeply moralistic side, so if you talk to him you will hear a great deal of passionate talk about how cruel and insensitive our society is. He is frequently frustrated by people who seem (to him) to be too complacent about injustice. If you asked him if he is happy, he would say no. In large part, this is because he thinks of happy people as giddy, superficial types and he has never been like that. However, it also reflects his sense that it would be indecent for him to be happy in the face of the misery he confronts daily in his work.

Nonetheless, the negative claims he makes are the expression of Paul's System 2. His personal perspective is fairly positive. He loves his wife and she is as committed as he is to the work they do. He is getting recognition from important philanthropists for his efforts. Although he deals with many sick, distressed people, he is himself in good health and has learned to take days off and allow himself to do things he likes - a good strategy for preventing burnout. Although he claims to be pessimistic about the future, at a deeper level he is not actually all that worried. He is fairly sure his clinic can continue to operate for the foreseeable future at least as well as it has been. In short, though he denies it, and though he may superficially strikes some people as unhappy, he is actually quite happy. 
Published 2018 In: Berys Gaut and Matthew Kieran (eds.) Philosophy and Creativity (New York: Routledge).

The lesson here is important. If we take individuals like Paul as our exemplars of negative experience, we will not grasp the real plight of those who occupy negative perspectives and we will acquire a false sense of what can be accomplished by individuals who suffer.

\section{$\S 5$ Conclusion}

Many people believe that negative psychological experiences (which are not the same as adversity) can have extrinsic prudential value. Indeed, there is some reason to believe that negative psychological experiences offer artists certain kinds of insights. However, the interesting question is whether individuals are ever in the position to reasonably judge prospectively that such experiences have sufficient extrinsic prudential value to make them worth choosing or enduring (when they could be avoided). I think that sometimes individuals clearly are in such a position and it can certainly make sense sometimes to choose lesser happiness for the sake of other goods. But we must be careful how we approach this topic. It is one thing to choose to forgo a highly positive perspective, and quite another to embrace a highly negative one.

We need to ask whether the goods that come with negative experiences are sufficient to outweigh the bad. We need to make sure that there is not another, less negative path to the same goods. We need to be aware of the strong tendency towards hindsight bias in the narratives of people who have been through tough experiences.

Most importantly, however, if we are to assess negative experiences properly, we need to be clear what kind of experiences we have in mind. Although mildly negative experiences may be worth enduring, especially if they seem to help a person produce 
Published 2018 In: Berys Gaut and Matthew Kieran (eds.) Philosophy and Creativity (New York: Routledge).

things she values, it is much more doubtful that extremely negative experiences are worth it. Because we so often confuse the two, discussions of this topic remain superficial. But given that much of the debate in the realm of creativity is sparked by the high incidence of affective illness in this population, and given that affective illness typically leads to the more severe forms of negative experience - to suffering or extreme suffering-it is important to recognize the differences. Whatever extrinsic value milder negative experiences may have, it is unlikely that suffering in my defined sense has prudential value. On my view, choosing to endure such states for the sake of art makes no prudential sense even when we acknowledge the great prudential value of creative expression.

\section{Bibliography}

Ackermann, R. and R. J. DeRubeis, 1991, Is depressive realism real? Clinical Psychology Review 11: 565-585.

Alloy, L. B. and L. Y. Abramson, 1979, Judgment of contingency in depressed and nondepressed college students: Sadder but wiser? Journal of Experimental Psychology: General 108: 4: 441-487.

Andreasen, N. C., 1987, Creativity and mental illness: prevalence rates in writers and their first degree relatives, American Journal of Psychiatry 144: 1288-92.

Beck, A. and B. Alford, 2009, Depression: Causes and Treatment 2nd edition, Philadelphia: University of Pennsylvania Press.

Dobson, K. and D. Pusch, 1995, A test of the depressive realism hypothesis in clinically depressed subjects, Cognitive Therapy and Research 19: 2: 170-194. 
Published 2018 In: Berys Gaut and Matthew Kieran (eds.) Philosophy and Creativity (New York: Routledge).

Elliot, C., 2000, Pursued by happiness and beaten senseless: Prozac and the American dream, The Hastings Center Report 30: 2: 7-12.

Evans, J. and K. Frankish, 2009, eds., In Two Minds: Dual Processes and Beyond, Oxford: Oxford University Press.

Gaut, B., 2012, Creativity and rationality, Journal of Aesthetics and Art Criticism, 70: $259-70$.

Haaga, D. and A. Beck, 1995, Perspectives on depressive realism: Implications for cognitive theory of depression, Behaviour Research and Therapy 33: 41-48.

Hassin, R., J. Uleman and J. Bargh, 2006, eds. The New Unconscious, Oxford: Oxford University Press.

Jamison, K. R., 1989, Mood disorders and patterns of creativity in British writers and artists, Psychiatry: Interpersonal and Biological Processes 52: 125-34. 1996, Touched with Fire: Manic-Depressive Illness and the Artistic Temperament, New York: Simon \& Schuster.

Kahneman, D., 2012, Thinking Fast and Slow, New York: Farrar, Strauss and Giroux.

Kaufman, J. C. and J. Baer, 2002, I bask in dreams of suicide: mental illness, poetry, and women, Review of General Psychology 6: 271-286.

Kieran, M., 2014, Creativity, virtue and the challenges from natural talent, ill-being, and immorality, Royal Institute of Philosophy Supplement 75: 203-30.

Kramer, P., 2000, The valorization of sadness, The Hastings Center Report 30: 2: 13-18.

— , 2005, Against Depression, New York: Viking.

Kyaga, S. et al., 2011, Creativity and mental disorder: family study of 300,000 people with severe mental disorder, British Journal of Psychiatry 199: 373-9. 
Published 2018 In: Berys Gaut and Matthew Kieran (eds.) Philosophy and Creativity (New York: Routledge).

,2013, Mental illness, suicide and creativity: 40-Year prospective total population study, Journal of Psychiatric Research 47: 83-90.

Ludwig, A. M., 1994, Mental illness and creative activity in women writers, American Journal of Psychiatry 151:1650-1656.

Melville, H., 1996 [1852], Pierre or The Ambiguities, Introduction and notes by William C. Spengeman, New York: Penguin Books.

Morris, W. N., 1999, “The Mood System,” In: Kahneman, Diener, and Schwarz eds., Well-Being: The Foundations of Hedonic Psychology, New York: Russell Sage Foundation, 169-189.

Peterson, C., 2006, A Primer in Positive Psychology, New York: Oxford University Press.

Post, F., 1996, Verbal creativity, depression and alcoholism: an investigation of one hundred American and British writers, British Journal of Psychiatry 168: 545-55.

Richards, R., 1981, Relationships between creativity and psychopathology: An evaluation and interpretation of the evidence, Genetic Psychology Monographs 103: 261324.

- 1988, Creativity in manic-depressives, cyclothemes, their normal relatives, and control subjects, Journal of Abnormal Psychology 97:281-8.

Schacter, D., 1996, Searching for Memory: the Brain, the Mind, and the Past, New York: Basic Books.

Shapiro, P. J. and R. W. Weisberg, 1999, Creativity and bipolar diathesis: common behavioral and cognitive components, Cognition and Emotion 13: 741-762.

Stanovich, K. E. and R. F. West, 2000, Individual differences in reasoning: 
Published 2018 In: Berys Gaut and Matthew Kieran (eds.) Philosophy and Creativity (New York: Routledge).

Implications for the rationality debate, Behavioral and Brain Sciences 23: 645-65. Verhaeghen, P. and R. Khan, and J. Joormann, 2005, Why we sing the blues: the relation between self-reflective rumination, mood, and creativity, Emotion, 5: 2: 226-232.

\footnotetext{
${ }^{1}$ Some studies suggest links with other mental illnesses, including schizophrenia. For simplicity, however, I focus here on bi-polar disorder and uni-polar depression. Although some people continue to research potential links between schizophrenia and creativity, many theorists have concluded that the appearance of a link in the past was really just a reflection of the high rate at which people with bi-polar disorder were misdiagnosed with schizophrenia.
}

I do not offer a definition of creativity here, since I rely almost exclusively on studies of people who are already widely recognized as having artistic talent.

${ }^{2}$ Although impressive, the research linking artistic creativity and mental illness has nonetheless been challenged in various ways. I do not explore those challenges here since I am interested in the hypothetical: What would it mean if, for a particular person, it were the case that negative affect were necessary for creativity? For critical discussions of this literature see Kieran (2014) and Gaut (2012).

${ }^{3}$ I use 'well-being' to refer to the special kind of value picked out by the locution 'good for so-and-so.' That which is good for a person is that which benefits her and is in her interests. That which is bad for her is harmful and against her interests. I also occasionally use 'welfare,' and 'prudential value' as alternative ways of referring to the same kind of value. 
Published 2018 In: Berys Gaut and Matthew Kieran (eds.) Philosophy and Creativity (New York: Routledge).

${ }^{4}$ For example, lithium, the most common treatment for bi-polar illness can cause weight gain, dry mouth, and hand-tremors. See https://www.nim.nih.gov/medlineplus/druginfo/meds/a681039. html\#side-effects. (Accessed July 1, 2016). SSRIs, the most common medications for depression, cause sexual dysfunction in 60\% of patients (Beck \& Alford 2009: p.273).

${ }^{5}$ However, there is an important sense in which I do assume that no simple version of desire-satisfactionism is true. If it were, then if a person wanted to risk everything for the sake of her art, then doing so would by definition make her better off no matter how much she suffered in the process. I do not find this plausible, but I cannot say more in defense of this claim here.

${ }^{6}$ See also Shapiro \& Weisberg (1999).

${ }^{7}$ One interesting study (Verhaeghen et al. 2005) investigated and found support for the idea that self-focused ruminative thought might lead to (1) negative affect and depression, on the one hand, and (2) enhanced creativity, on the other. On this model it should, in principle, be possible to separate the two effects of rumination. Thus the authors of the study describe the implications of their work as, "the cliché that the artist must suffer is not true." However, that is too strong. Even if the two are separable in theory, if we do not currently have good ways of separating them in practice, then for the foreseeable future they may still be bundled together for creative individuals. Even if the type of necessity at issue is not metaphysical or natural necessity, practical necessity is still important. 
Published 2018 In: Berys Gaut and Matthew Kieran (eds.) Philosophy and Creativity (New York: Routledge).

${ }^{8}$ It is also important to note that more than one theory might be true, i.e. there might be more than one way that negative affect contributes to artistic production. For example, something like the bundle theory proposed by Verhaeghen et al. (2005) might be true, and it might also be true that artists carry away from their experiences insights that are valuable (a version of the special ingredient view). If that were the case, then even if it became possible to separate elements of the bundle, it might still be true that negative affective experiences have significant extrinsic value that would be lost with the use of medications to repress negative affect.

${ }^{9}$ Although Jamison (1996) is certainly convinced of the positive value of negative affect, her own proffered explanations of the value mostly locate it in relation to the excesses of manic states. On her view, negative affect is valuable because it corrects for these excesses. So it is not clear from her account whether negative affect would have value for people with unipolar depression.

${ }^{10}$ Jamison offers numerous examples including Roethke, "In a dark time, the eye begins to see," Shelley, "Most wretched men/Are cradled into poetry by wrong/ They learn in suffering what they teach in song," and Virginia Woolf who writes "It is always a question whether I wish to avoid these glooms...There is an edge to it which I feel is of great importance... One goes down into the well and nothing protects one from the assault of truth." (Jamison 1996: 115, 118). The attitudes of artists towards their own negative experiences provide us with a reason for wanting to explore the relationship more. However, as I emphasize in the next section, their claims cannot simply be accepted at face value, since individuals may suffer from retrospective biases. 
Published 2018 In: Berys Gaut and Matthew Kieran (eds.) Philosophy and Creativity (New York: Routledge).

${ }^{11}$ Although Jamison (1996) clearly believes in the value of emotional extremes, she is not very clear about the nature of that value. At times she suggests that artists gain important insights, but she doesn't elaborate on what these insights might be or how they might contribute to art. I have tried in these two paragraphs to put forward a view of my own about how that might work. At other times, she emphasizes the value of shifts in mood, and still other times the wealth of cognitive material that might be available to the mind of someone who frequently inhabits different mood states (which seems to be the point about memory and mood congruence that I discuss next).

${ }^{12}$ Kramer, (2000). Kramer's piece is a response to Carl Elliot (2000) who argues that many negative affective states that seem like depression are really instances of alienation - an appropriate response to the modern world.

${ }^{13}$ Although Kahneman uses the labels 'System 1' and 'System 2,' the terms originate with Stanovich and West (2000). My own thinking about and understanding of the dual process view has been shaped not only by Kahneman, but also by the essays in Hassin et al. (2005) and Evans et al. (2009).

${ }^{14}$ Though this is not to deny the importance of System 2. Many affective phenomena are refined by, and given a more concrete formulation by, System 2. For example, on my view, particular emotions begin as System 1 assessments, but often gain an additional layer of complexity from System 2. However, this is all compatible with my claim that personal perspectives are generated by System 1, and that personal perspectives are, for the most part, a System 1 phenomenon. 
Published 2018 In: Berys Gaut and Matthew Kieran (eds.) Philosophy and Creativity (New York: Routledge).

${ }^{15}$ Although a positive perspective is intrinsically good, it is not the only good thing in a life, and therefore not in itself a guarantee of a good life overall. Consider the example of someone living in an experience machine who has a positive perspective. I maintain that it is typically worse to be in an experience machine than not, but if you are going to be in an experience machine you are better off with a positive perspective than with a negative one. This is what I mean when I say that a positive perspective is good in itself.

\section{Author Bio:}

Jennifer Hawkins is Associate Research Professor in the Department of Philosophy and a Faculty Affiliate of the Trent Center for Bioethics, Humanities, and History of Medicine, at Duke University, USA. She is currently working on a book about well-being. 